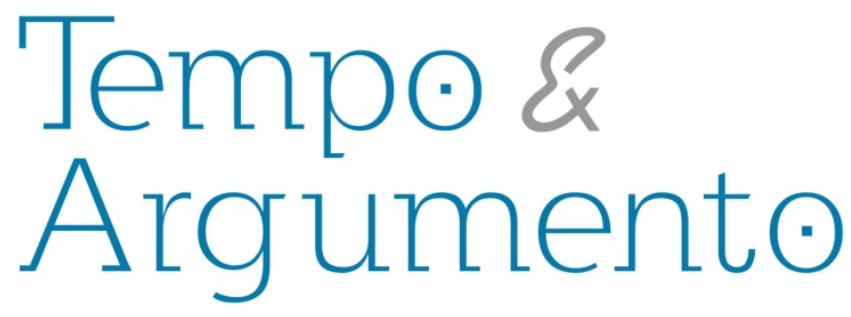

\title{
La Historia Social de la familia en España y su repercusión en la Didáctica de las Ciencias Sociales ${ }^{1}$
}

\begin{abstract}
Resumen
La Historia Social en España comenzó a desarrollarse de forma tardía, respecto a otros países europeos. Si bien ha alcanzado una destacada relevancia, desde el último tercio del siglo XX. En particular el estudio de las familias, en sentido amplio, ha experimentado un gran auge respecto a temas diversos: demografía, élites, migraciones, conflictos. Sin embargo, la repercusión de estos avances historiográficos ha sido escasa en el ámbito de la Didáctica de las Ciencias Sociales. Las experiencias e investigaciones en Educación Infantil, Primaria y Secundaria, que han fijado su atención en la importancia de la familia, muestran que es posible aunar la disciplina histórica y su didáctica de forma exitosa. La familia como primer nivel afectivo y educativo del alumno tiene un enorme potencial didáctico, que puede ayudar a fomentar el pensamiento crítico y el interés por lo histórico.
\end{abstract}

\author{
Juan Hernández Franco \\ Doctor en Historia por la Universidad \\ de Murcia (UMU). Catedrático de \\ Historia Moderna y codirector del \\ Seminario Familia y Élite de Poder en la \\ Facultad de Letras de la UMU. \\ jhf@um.es
}

Raimundo A. Rodríguez Pérez

Doctor en Historia por la UMU. Profesor Contratado Doctor de Didáctica de las Ciencias Sociales en la Facultad de Educación de la UMU. raimundorodriguez@um.es

Palabras clave: Historia Social; Familia; España; Didáctica de las Ciencias Sociales.

\section{Para citar este articulo:}

HERNÁNDEZ FRANCO, Juan; RODRÍGUEZ PÉREZ, Raimundo A. La Historia Social de la familia en España y su repercusión en la Didáctica de las Ciencias Sociales. Revista Tempo e Argumento, Florianópolis, v. 6, n.11, p. 254-277, jan./abr. 2014.

\section{DOI: $10.5965 / 2175180306112014254$}

http://dx.doi.org/10.5965/2175180306112014254

\footnotetext{
1 Este trabajo es resultado de tres proyectos de investigación: HAR2010-21325-C05-01 "Realidades familiares hispanas en conflicto: de la sociedad de los linajes a la sociedad de los individuos", del Ministerio de Ciencia e Innovación de España (MICINN); EDU2012-37909-C03-03“La evaluación de las competencias básicas en Educación Secundaria Obligatoria desde las ciencias sociales”, del MICINN; y 15300/PHCS/10 Nobilitas. Estudios y base documental de la nobleza del Reino de Murcia, siglos XV-XIX. Segunda fase: análisis comparativos, de la Fundación Séneca, Agencia de Ciencia y Tecnología de la Región de Murcia.
} 


\section{Social History of the family in Spain and its impact on Teaching of Social Sciences}

\begin{abstract}
Social History in Spain began to develop late, compared to other European countries. Yet, it has achieved a strong relevance, since the last third of the twentieth century. In particular the study of families, in a broad sense, has boomed on various topics: demography, elites, migration, conflict. However, the impact of these historiographical progress has been scarce in the field of Teaching Social Sciences. Experiences and research in Kindergarten, Primary and Secondary School, which have fixed their attention on the importance of family, show that it is possible to combine the historical discipline and its teaching successfully. The first family as emotional and educational level of the student teaching has enormous potential that can help foster critical thinking and interest in the historical.
\end{abstract}

Keywords: Social History; Family; Spain; Teaching of Social Sciences.

\section{A história social da família na Espanha e seu impacto sobre o Ensino de Ciências Sociais}

\begin{abstract}
Resumo
A História Social na Espanha começou a se desenvolver tarde, em comparação com outros países europeus. Embora se tenha conseguido uma grande importância, desde o último terço do século XX. Em particular, o estudo das famílias, em um sentido amplo cresceu em vários temas: demografia, elites, migração, conflitos. No entanto, o impacto destes progressos historiográficos tem sido escassa no campo do Ensino das Ciências Sociais. As experiências e pesquisas em Educação Infantil, Primária e Secundária, que fixaram a sua atenção na importância da família, mostram que é possível combinar a disciplina histórica e seu ensino com sucesso. A família como primeiro nível afetivo e educativo do aluno tem um enorme potencial didático que pode ajudar a promover o pensamento crítico e interesse no histórico.
\end{abstract}

Palavras-chave: História Social; Família; Espanha; Ensino de Ciências Sociais. 


\section{Introducción: la Historia Social en España}

En Europa, desde mediados del siglo XX, la Historia Social se convierte en un campo específico y con enorme repercusión, en buena medida como una elección metodológica crítica frente a la historia política. Diferentes corrientes teóricas y metodológicas, primero en Inglaterra impulsada por el materialismo de los British Marxist Historian (KAYE, 1989)- y en Francia -bajo el auspicio de la escuela de los Annales-, y con posterioridad en Alemania -patrocinada por la escuela de Bielefeld y por el círculo de Heidelberg (SCULIN, 1991)- e Italia -favorecida por la historia social del movimiento obrero y la microhistoria (GOZZINI, 1991)- hicieron posible el desarrollo de una pujante historia social o historia de la sociedad, cuyos puntos de vista determinan especialmente- el curso de otros territorios de la Historia, como la Historia de la política, la Historia de las ideas e incluso la Historia de la cultura.

En comparación con el avance y situación de la Historia Social en los países recién citados, conforme señala Julián Casanova (1991, p. 157) en el apéndice de su libro La Historia Social y los Historiadores, debe hablarse de "El secano español”. Además y esto es de enorme relevancia, la consolidación de la Historia Social no se ha debido a la existencia o forja de una propuesta teórica o de corrientes metodológicas. El despunte de la Historia Social, ciertamente vinculado a la recepción del materialismo histórico inglés y la escuela francesa de los Annales, debe mucho al magisterio de historiadores con destacada influencia sobre el resto de los profesionales, como han sido Jaume Vicens Vives y su discípulo Josep Fontana (MUÑOZ, 1997; PEIRÓ MARTíN, 2013), Antonio Domínguez Ortiz (1973) y José Antonio Maravall (1979). Sus estudios, centrados fundamentalmente en las "capas sociales altas", han allanado el terreno para conocer la organización social, los grupos sociales, y la conflictividad y las tensiones sociales. A partir sus trabajos, ciertamente la historia social comenzó también a deslizarse hacia la historia desde abajo -conforme a la conocida propuesta de E. P. Thompson- y han ido surgiendo bastantes y meritorios trabajos de carácter regional y local, aunque sin prestar la importancia que se debía a la teoría y a los análisis empíricos. 
En relación a lo que acabamos de exponer, cuando al finalizar el siglo XX Roberto Fernández hace balance sobre el estado de la historia social, manifiesta que era una "historia en construcción". Realiza esta afirmación a partir de un riguroso examen de lo producido por el modernismo catalán. Su valoración es con pocos matices extensible al estado de la Historia Social en España. Es un campo sobre el que frecuentemente recae o incide la duda de su contenido o alcance, por esas complejas fronteras que mantiene actualmente la Historia Social con la Historia Cultural, con la Historia Política y con la Historia Económica. Hecho este que afortunadamente, permite comenzar a poner en tela de juicio la tautología de que toda historia por definición es social. No obstante encontrarse la Historia Social en estado de construcción, tiene bastante bien delimitados sus objetos de análisis: "lo social”, entendido como lo hace Jurgen Kocka, es decir, los fenómenos más específicamente sociales de las comunidades humanas constituidas. Así pues, la historia social está configurada por una colección de problemas históricos concretos, entre los que están como más destacados: la movilidad social, el cambio social, la socialización de la persona, los grupos y las clases sociales, las formas de la vida privada, el trabajo, los conflictos sociales, las minorías étnicas, la marginalidad... y, por supuesto, el tema que nos va a ocupar principalmente en el presente trabajo: la historia de la familia (FERNÁNDEZ DÍAZ, 1999).

Temas que a lo largo de lo que llevamos de siglo XXI se han ido ampliando, como pudimos comprobar, cuando la principal revista de la especialidad editada en España, Historia Social, el año 2008 hizo un arqueo de las temáticas que se integran bajo el denominador Historia Social. Con tal fin la dirección de la revista encuestó a un amplio número de historiadores sociales españoles y extranjeros. En concreto, Jorge Uría, en su artículo "La Historia Social Hoy", nos indica la complejidad y amplitud de los territorios que interesan a quienes trabajan en Historia Social: los procesos de aprendizaje social; los diversos tipos de sociedad; la vida cotidiana; el cuerpo, la sexualidad y el género; los mecanismos sociales de consenso, de desviación y de delito; los mecanismos de integración religiosa; los fenómenos de estratificación y estructura de clase; el trabajo; los medios de comunicación social; los fenómenos revolucionarios, la conflictividad y, por supuesto, la familia (URIA, 2008). 
En consecuencia, y podríamos seguir aportando más pruebas, la Historia Social y en concreto quienes la practican consideran a la Historia de la Familia como uno de los apartados que forman la gran "acumulación y fragmentación" (VAN DER LEYDEN, 2008) de cuestiones y temas que la configura. Y es que a la Historia de la Familia, como ocurre con otras parcelas de la Historia Social, también bordea territorios próximos a otras parcelas de la Historia, como son la Demografía Histórica, la Historia Económica o la Historia Cultural. Asimismo mantiene relaciones bastante fluidas con otras disciplinas sociales, especialmente con la Antropología y la Sociología, necesarias para paliar la "miseria" teórica que suele afectar a la Historia, aunque hay que ser cuidadoso en la aceptación acrítica de los métodos de las otras disciplinas por parte de la Historia Social, pues a veces puede acabar haciéndose historia antisocial al anular el peso de lo colectivo a la irreductible existencia de lo individual (SEIDMAN, 2007).

\section{La Historia Social de la familia en España: evolución y perspectivas}

El panorama de la Historia Social de la Familia dentro de la historiografía española no ha sido diferente. Un enorme retraso respecto al desarrollo alcanzando por este subcampo a partir de 1960 en Francia, debido a los trabajos de P. Ariès sobre la sociabilidad y sentimientos frente a la infancia, a los análisis demográficos que inició L. Henry y posteriormente continuó P. Goubert, y a los análisis predominantemente socioculturales de E. Le Roy Ladurie, A. Burguière y J-L. Flandrin; en Inglaterra, donde junto a los estudios de L. Stone, mostrándonos cómo fue Inglaterra el país donde aparece la familia moderna tal y como hoy lo conocemos, destacan por su enorme influencia los estudios de la familia que desde el año 1964 llevó a cabo el Cambridge Group for the History of Population and Social Structure, y que resultaron de tanta trascendencia para determinar los tipos de familia a partir de las características que posee la unidad de residencia -muy duramente criticado respecto al modelo de familia mediterránea por $\mathrm{D}$. Kertzer y C. Brettell (1987)- y para conocer las prácticas demográficas y sociales de las familias, bastante distintas a las de la etapa industrial tras la desaparición de la familia patriarcal, como probó P. Laslett en su libro The World We Have Lost; o en Alemania, donde desde la década de los setenta del siglo XX en vez de determinar los tipos de 
Fue en los inicios de la década de 1980 cuando comenzó a estudiarse la familia en España conforme a las metodologías que acabamos exponer. El pionero e impulsor -si exceptuamos los trabajos de los hispanistas J. Casey y B. Vicent- va a ser Francisco Chacón Jiménez, quien en el primer libro en el que se analizaba el estado de los estudios de la familia, publicado el año 1987, determinó con gran acierto que la historia de la familiar era "una historia por hacer" (CHACÓN JIMÉNEZ, 1987).

Estar por hacer, no implicaba que no hubiera una pequeña e interesante base, fruto de la influencia de la demografía histórica francesa y del grupo de Cambridge, que había permitido desde 1978 a 1985 la aparición de sugerentes propuestas sobre modelos demográficos regionales -debido al minucioso trabajo de Antonio Eiras y el grupo de historiadores que trabajan junto a él en la Universidad de Santiago de Compostela-; los modelos matrimoniales de la Península Ibérica, cuya configuración pasaba por un estrecha relación con los modelos demográficos y los sistemas familiares; y la antropología social de la familia, orientada fundamentalmente a determinar la relación existente entre sistemas de herencia, alianzas matrimoniales y parentesco. A partir de 1985 y durante los primeros años de la siguiente década, la masa crítica de la historia social de la familia continuó incrementándose con la complejidad y diversidad que presenta la familia mediterránea -en línea con las objeciones planteadas por D. Kertzer-; las relaciones sociales de producción y parentesco, debido al fuerte impulso que la antropología de la familia daba a estos temas, y la especificidad de las formas familiares de determinados grupos sociales, como era en concreto la nobleza (CHACÓN JIMÉNEZ, 1990, 1991 y 1992).

Asentada la historia social de la familia en torno a las temáticas citadas, y consolidado su estudio con la aparición de importantes seminarios de estudios (Murcia, Mallorca, Madrid, Barcelona, Santiago de Compostela) lo que realmente faltaba era plantear propuestas y nuevas perspectivas de investigación, como ya habían hecho por ejemplo Tamara Haraven y Andrejs Plakans para la historia de la familia desde una 
Francisco Chacón propuso, a comienzos de los años 90 del pasado siglo, ese programa que se dirigía a realizar una nueva definición de la estructura social de la España del Antiguo Régimen a través de la familia. Básicamente en dos grandes objetivos: 1) pasar de la historia de las familia a la historia de las familias; 2) la problematización de la historia de la familia mediante la interrelación de diversas variables a considerar. Y para lograr estas dos grandes propuestas, a su vez era necesario considerar: a) que alianza, familia y parentesco constituyen denominadores comunes en los mecanismos de reproducción y control social; b) que es necesario plantearse un análisis de la familia socialmente diferenciado en base a la estructura y tamaño de la familia por un lado y de otro los grupos socioprofesionales; c) determinación del ciclo de vida. Resumiendo al máximo, Francisco Chacón pretendía poner en marcha un proyecto que permitiera el conocimiento de la estructura familiar a través del ciclo de vida, de la dimensión económica y de las relaciones de parentesco, de forma que pudiera ser captada en un entorno social amplio -cuando menos en el de las redes sociales en las que se inserta- y conocer sus estrategias de reproducción social (CHACÓN JIMÉNEZ, 1991, p. 89).

¿Cuál ha sido el resultado de este programa? Excelentes referencias para verificarlo en el ámbito de España constituyen respectivamente las obras coordinadas por: Francisco García González, Historia de la Familia en la Península Ibérica (Siglos XVI-XIX). Balance regional y perspectivas (2008); Francisco Chacón Jiménez y Juan Hernández Franco, Espacios sociales, universos familiares: la familia en la historiografía española (2007); F. J. Lorenzo Pinar, La familia en la Historia (2009); y Francisco Chacón y Joan Bestard,Familias. Historia de la sociedad española (de final de la Edad Media a nuestros días) (2011). Tomando como referencias el primero y el último de los libros que acabamos de citar, pues permiten ver la progresión de los estudios a nivel regional y en su conjunto, al tratarse Familias... del primer gran trabajo que pretende conocer la sociedad española de los últimos setecientos años a través del prisma de la historia de la familia, los resultados que podemos poner de relieve son los siguientes. 
El primero es que a nivel historiográfico, la historiografía española sobre la familia ha avanzado notablemente, y que ya no se puede hablar de la situación de páramo o casi ausencia de trabajos que había a comienzos de los años ochenta del siglo XX. De forma bastante proporcionada, en la práctica totalidad de las Universidades españolas han ido surgiendo centros, seminarios, equipos interesados en la familia, lo cual ha hecho posible que, cuando menos cuantitativamente, podamos trazar una geografía de las familias bastante segura para la Península Ibérica. Aunque ciertamente, diversos elementos como el derecho y la tradición jurídica, la formas políticas y los impulsos económicos no permiten decir que existe un modelo único de familia española (CHACÓN JIMÉNEZ, 2008, p. 15); más bien los elementos citados y el peso que la experiencia posee en las sociedad a nivel de cada uno de los territorios históricos, nos puede llevar a hablar de familias españolas, con rasgos propios del mundo mediterráneo, atlántico o interior, dentro de las que a su vez habría que diferenciar entre las asentadas en el mundo urbano y el mundo rural -Galicia y Asturias es un excelente ejemplo con su diverso muestrario de tipos familiares, con regiones en las que hay un destacado número de familias troncales y en cambio otras, según nos vamos alejando de las tierras interiores y acercándonos a la costa, con predomino de la familia nuclear (PÉREZ GARCíA, 2008)- y por supuesto influenciadas por su posición o estatus social y los valores culturales con los que se identifican.

Segundo, confirmado tanto por la opinión de los historiadores como por la producción historiográfica, la historia de la familia cada vez más se desentiende de análisis relacionados exclusivamente con las cuestiones demográficas -como hacía en los años ochenta del siglo XX-, pues la problemática relacional de la familia gira en torno a perspectivas demográficas, económicas, sociales y culturales. Ferrer (2008) añade algunas más: mentalidades, política, reproducción material y trabajo, reproducción social..., ya que lo que busca es una plena integración con la realidad de la que depende. Posiblemente, en una acertada frase, F. García indica la bóveda de clave de la historia de la familia, que ha pasado de su estudio como célula de sociabilidad en la que solo interesaba como una unidad de residencia a otra en la que está plenamente inserta en la sociedad, en la que "es a la vez reina y prisionera” (GARCÍA GONZÁLEZ, 2008, p. 27). 
En este camino hacia "lo social", ha sido clave la incorporación de diversas propuestas metodológicas. Empezando por la reconstrucción de "genealogías sociales", pues la tendencia de la historia de la familia clásica, de reconstruir familias a nivel de datos demográficos de individuos, ha dejado paso a la reconstrucción de contextos familiares y sociales en los que se integran las personas como componentes de familias que forman parte de redes y grupos sociales heterogéneos o desiguales en estatus. Continuando, aunque no sea estrictamente metodológico, pero su uso ha reorientado el vínculo entre la historia de la familia y la antropología social clásica, con la consideración del parentesco como algo más que un lazo afectivo, pues no es solo un orden natural, sino especialmente un orden social, ya que los vínculos de afinidad y sangre están en estrecha relación con las prácticas culturales, la organización social y las relaciones sociales (BESTARD CAMPS, 1998). Las aportaciones metodológicas que facilitan el camino hacia la historia social son, desde luego, numerosas. Entre ellas destaca la llamada microhistoria social de la familia, que supone conjugar el análisis de individuos con trayectorias familiares, a través de esbozos próximos a la biografía, aunque con el objetivo de explicar la organización social (AMORIN, 1992).

Tercero, la familia al no ser un campo exclusivamente de la Historia, sino abierto a bastante ciencias sociales (Antropología Social, Sociología, Derecho, Etnografía, Demografía Histórica) se ha liberado de la estrecha relación que con excesiva frecuencia se establece entre el problema histórico y una temporalidad más académica que real. Por ese motivo, como se puede comprobar en el citado libro Familias..., los tiempos no son edades, sino tendencias como continuidad, permanencia, tensión, evolución, transformación e incluso revolución, de forma que a través de las mismas es mucho más fácil entender lo que significa el hecho social de las familias.

En cuanto a los temas a los que presta la atención, sin descuidar los clásicos como formas familiares, matrimonio, sistemas de filiación y parentesco, sistemas de herencia y sucesión, u otros más recientes como familias y grupos sociales, prácticas familiares, familia y género, parentela y amistad, familia y redes sociales, discursos sobre la familia, ideales familiares, moral sexual, familias y culturas políticas, representaciones de la familia, los nuevos valores de la adopción y de la paternidad, la familia en la era 

factores, en realidad, son imprescindibles para comprender la experiencia social de la familia, como son: jerarquía social, capital relacional, relaciones de producción y relaciones de parentesco. Pues a través de los mismos se consigue la explicación de la organización social -por supuesto desigual- en la que se inserta la familia (CHACÓN JIMÉNEZ; BESTARD CAMPS, 2011).

La situación de la historia social de la familia evidencia claramente que ha dejado atrás la etapa en la que estaba “por hacer”. Pero también qué queda aún por hacer y que en modo alguno es válida la propuesta de Nara Milanich (2007), cuando sostiene que los estudios de familia han caído prematuramente en una tranquila senectud. La fase real de la historia social de la familia creemos que la refleja perfectamente el sustantivo evolución. Una evolución que corre paralela al lógico deseo de la sociedad actual de conocer el pasado y el presente de la familia, pues vivimos en unos momentos de transformaciones respecto a los valores y prácticas de la familia. Por esa razón, es necesario que la didáctica emplee los conocimientos generados por las ciencias sociales que se ocupan de la familia, para trasmitirlos en forma de conocimientos claros y ordenados a los alumnos.

\section{Un reto viable: de la Historia Social a la Didáctica de las Ciencias Sociales}

El divorcio entre historia investigada e historia enseñada se debe a que la primera aboga por líneas muy específicas de estudio, en tanto la segunda se centra sobre todo en los discursos nacionales. Resumiendo mucho podría afirmarse que esa historia enseñada, al menos en países como España, sigue anclada al paradigma decimonónico que primaba cuando surgió la enseñanza pública: el positivismo. Esta tendencia historiográfica ha mantenido, hasta mediados del siglo XX, un peso más que considerable en el ámbito académico e investigador. Tendría que llegar el materialismo histórico y la Escuela de Annales para fomentar una historia no tan sólo político-factual, sino más social y 
los currículos y, por tanto, en los libros de texto de forma abrumadora. Con esa dispar evolución resulta harto complicado que los notabilísimos avances que se han producido en la investigación histórica se trasladen a las aulas, desde los niveles educativos iniciales y hasta la propia universidad. Si bien es cierto que existen iniciativas, tanto desde la Historia como desde la Didáctica de las Ciencias Sociales, que llevan años empeñadas en unificar ambas líneas de conocimiento (MOLINA; RODRÍGUEZ; SÁNCHEZ, 2013).

Como se ha indicado anteriormente, la Historia Social en España, especialmente los estudios de tipo familiar, han alcanzado un sobresaliente desarrollo en las últimas décadas. A pesar del atraso respecto a otros países europeos, los historiadores españoles dedicados al estudio de lo social, junto a la influencia de hispanistas franceses y anglosajones, han hecho aportaciones singulares. Tanto es así que la Historia que se viene haciendo en España, especialmente en lo referido al estudio de los períodos medieval, moderno y contemporáneo, no sólo ha dejado de depender de escuelas y referentes foráneos, sino que se ha erigido en un prestigioso modelo internacional. Ello se debe a la aplicación de rigurosas metodologías de estudio, aprovechando la enorme riqueza de los archivos y bibliotecas de España y territorios ligados a ella por motivos históricos y culturales, es decir su antiguo Imperio. A tales éxitos de la historiografía hecha desde España, en suma el proceso de modernización hasta colocarse en la vanguardia, ha contribuido notablemente la Historia Social, en sus múltiples vertientes, ya aludidas. Las claves de esos éxitos han sido la interdisciplinariedad, con un diálogo crítico y constructivo con otras ciencias sociales (Antropología, Sociología, Derecho, Economía), así como con otras tendencias historiográficas, tan cercanas y lejanas a la vez durante décadas (Historia Política, Historia Cultural). Sin olvidar, el cada vez mayor alejamiento de decimonónicas divisiones temporales y espaciales.

Con todo, el balance también presenta sombras. Queda mucho por hacer, dado que la Historia es una ciencia que está en continua reelaboración. Además, si a partir de la década de 1970 la Historia Social, sobre todo de la familia, se convirtió en una tendencia 
que por fin la Historia Social había logrado una posición de cierta pujanza debe reinventarse ante la mayor atención de otros temas, en los cuales el estudio de la familia no tiene cabida, salvo quizá para épocas actuales. El problema que esto supone es que son sociólogos y antropólogos quienes pasan a tener un protagonismo casi absoluto. La demografía histórica no está de moda, si bien grupos de investigación consolidados y que han prestigiado estos estudios siguen vigentes, destacando los congresos internacionales y la revista que publica la ADEH (Asociación de Demografía Histórica). Quizá por la mayor cantidad de información que ofrecen las fuentes, buena parte de esos mismos estudiosos han virado hacia el análisis de los grupos sociales poderosos: noblezas, oligarquías, alto clero. No es que se hayan abandonado por completo las investigaciones sobre campesinos, artesanos, obreros o marginados, pero al menos en el ámbito del modernismo español su peso cualitativo ha decrecido. Tal fenómeno no tiene por qué ser negativo, pues demuestra que las élites aún deben ser revisadas a fondo, aprovechando el amplio bagaje de la Historia Social y sin dejar a un lado las cuestiones familiares.

Además del cambio de tendencia historiográfica, lógico por el paso de los años, la Historia Social se enfrenta a otro reto. Relegada a una posición secundaria en los currículos de ciencias sociales de todos los niveles educativos, resulta sin embargo necesaria para mitigar el peso aún omnipresente de la historia factual en la enseñanza. Dentro de la Historia Social parece evidente que los estudios sobre la familia en diversas épocas pueden coadyuvar a acercar al alumnado a su pasado, de una forma más procedimental y actitudinal. Sin embargo, esto no debe significar reducir el papel de la Historia Social de la familia a un mero complemento que ilustre cada bloque temático. Sin renunciar a unas mínimas nociones de cronología e historia política, lo familiar puede ser útil a la hora de enseñar cómo era la vida cotidiana de las diferentes civilizaciones, así como la huella que ha dejado en nuestro legado cultural. Entendiendo dicho legado en sentido amplio, esto es patrimonio material e inmaterial (ESTEPA, 2013), podemos hacer un uso mucho más significativo de la Historia Social, a partir de la célula básica de 

de Giovanni Levi (2010, p. 11), que fomentaron obras públicas y privadas. Observar qué grupos sociales y en qué coyunturas determinan el patrimonio de una ciudad o región, aunando así el interés por lo local, a menudo denostado, cuando es el recurso más accesible para fomentar el pensamiento crítico y la participación del alumnado. Conocer la evolución de cascos antiguos de cierta singularidad, ver qué les definía y cómo han llegado hasta nosotros, en función de: tipologías urbanas, períodos de pujanza económica, desastres naturales o especulación inmobiliaria. Esto puede derribar añejas fronteras disciplinares entre Geografía, Historia e Historia del Arte. Y puede hacer más fáciles unos programas culturalistas (PRO; MIRALLAES, 2009), en los que el alumno debe memorizar una inmensa cantidad de nombres, fechas y conceptos, de forma lineal y poco atractiva.

Así pues, partiendo de las limitaciones de unos decretos curriculares enciclopedistas, la Historia Social tiene mucho que ofrecer en la enseñanza de las ciencias sociales en diversos niveles educativos (GÓMEZ; MIRALLES, 2013). Ahora bien, sin una correcta formación disciplinar que ahonde en las fuentes, recursos y métodos que el historiador tiene a su alcance, difícilmente el docente podrá salir de la lección magistral y el libro de texto. Siguiendo la estela de otros modelos educativos, especialmente los de países anglosajones (BARTON, 2001), y aprovechando el rico acervo cultural español, la Historia Social de la familia no debe ser un fin en sí mismo, pero puede aproximar a la utilidad de las fuentes primarias (SEIXAS; FROMOWITZ; HILL, 2002). La introducción de éstas en el aula no implica una revolución, sino hacer uso de los múltiples recursos que las TIC ponen a nuestra disposición. Réplicas, visitas virtuales, colecciones documentales on line, hemerotecas ya están siendo usadas con éxito en otros países desde hace varias décadas. Por tanto, no se trata de inventar nada nuevo, más bien de aplicar a la idiosincrasia española lo que funciona en otros lugares. El éxito radicará en reducir la enorme cantidad de temas a tratar, seleccionando una muestra de aquellos más relevantes, con opciones como aproximarlos a problemáticas locales o regionales 
En suma, una visión de la historia que aborde temas tradicionales y otros nuevos buscando referentes próximos a la cosmovisión del alumno: su familia, su barrio, su ciudad... Hacer uso de fuentes primarias y secundarias en clase (FELIU; HERNÀNDEZ, 2011), que muestren la historia como algo vivo, pero con una metodología científica, como cualquier otra disciplina. El patrimonio, no sólo artístico, sino también el paisaje como legado a proteger por todos, deben ser elementos a tener en cuenta. Somos conscientes del carácter de propuesta que tiene este trabajo, es decir aún no predominante en las aulas, ni siquiera en las universitarias, donde hasta el máster o doctorado no se inicia a los alumnos en la investigación. No obstante, creemos factible trasvasar los resultados investigadores de la disciplina histórica, en este caso la Historia Social de la familia, a la Didáctica de las Ciencias Sociales. Esta última no puede seguir relegada a una posición esencialmente patriótica y por ende monolítica, como en el siglo XIX, cuando surgieron las escuelas públicas. Sólo con la colaboración entre historiadores y didactas los currículos y libros de texto podrán dejar de ser, en un plazo no muy lejano, la sucesión de lecciones de carácter abrumadoramente conceptual.

\section{La Historia Social de la familia: enseñar lo que se investiga}

Los estudios sobre la familia son un elemento clave para la Historia Social. Ya se ha señalado que no se limitan a obras cuantitativistas sobre número de hogares, matrimonios, hijos, etc. La familia es un concepto clave, sin el cual no puede entenderse ninguna sociedad pretérita o actual. Ayuda a explicar las formas de trabajo, sociabilidad, poder, religiosidad, en definitiva cómo vivían nuestros antepasados en un sentido diacrónico, es decir si eran capaces de adaptarse a nuevos contextos (movilidad, conflicto, ascenso y descenso social). Dicha relevancia ha sido tenida en cuenta a la hora de enseñar historia en Educación Infantil, Primaria y Secundaria (MIRALLES; MOLINA; ORTUÑO, 2011). En los niveles iniciales, todavía marcados por el egocentrismo del niño, la 
está comenzando a asimilar nociones como anterioridad y posterioridad, causa y efecto, alteridad (al comparar su biografía con la de sus compañeros).

En Educación Infantil, sobre todo en el segundo ciclo, se ha producido en los últimos años un importante avance, siendo la etapa educativa en la cual trabajar cuestiones didácticas relacionadas con la familia se ha introducido más tarde. Dejando atrás obsoletas ideas, derivadas de la pedagogía evolutiva de Piaget, que rechazaban la capacidad de abstracción en el niño de corta edad, se ha comprobado que haciendo uso de las herramientas y recursos necesarios, se puede iniciar en la comprensión de problemas de temporalidad histórica, sincronía y diacronía ya a edades tempranas, tal y como han demostrado Calvani, Egan y Cooper (TREPAT, 2011, p. 63). De hecho el Real Decreto 1630/2006, de 29 de diciembre, que establece la enseñanzas mínimas del segundo ciclo de Educación Infantil, expresa claramente la importancia de la familia como agente educativo y socializador, al ser junto a la escuela y, en menor medida, el municipio, el entorno más próximo del alumnado. Ahora bien, aunque la familia aparece citada en el tercer bloque de contenidos del área de Conocimiento del entorno su tratamiento en las aulas ha sido, en palabras de Miralles y Molina "mejorable" (2011, p. 98). Se alude a su relevancia, pero apenas se refleja en la legislación y, por ende, en los libros de texto (MIRALLES; MARTÍN, 2008). Tras analizar 4175 imágenes relacionadas con la familia, incluidas en 18 manuales de Infantil de seis de las principales editoriales españolas, los profesores Miralles, Delgado y Caballero (2008) comprobaron que el uso que se hacía de las mismas tiende a perpetuar la visión de una familia nuclear de clase media y raza blanca, esto es un modelo que ya no es el predominante. $\mathrm{Y}$ apenas un $7 \%$ de las imágenes tenía un tratamiento didáctico específico.

Frente a esa visión anticuada, debe procurarse que el alumno de Infantil se aproxime a la familia desde la perspectiva de la competencia social y ciudadana, con el fin de entender los distintos tipos de familia, sus rasgos culturales y étnicos. La ONU ya advirtió, en 1998, que el modelo tradicional de familia nuclear no recoge la amplia 
en un primer paso para la tolerancia, dentro de un marco social y educativo multicultural, en el cual el alumno debe respetar que existan unidades familiares diferentes a la suya, verlo como algo enriquecedor. La enseñanza de lo social y, en especial lo familiar, facilita la comprensión del mundo y la formación de futuros ciudadanos. Entre las actividades recomendadas para trabajar la familia en esta etapa educativa destaca la colaboración con las propias familias de los alumnos, esto es la llamada historia personal, con visitas de padres y abuelos al centro, mostrando sus experiencias vitales, formas de vida o tipos de vivienda. Reyes (2008, p. 366) aboga por cambiar la formación tradicional de los futuros docentes de Educación Infantil, como paso previo necesario para evitar que esos maestros perpetúen prejuicios sobre la familia. Apuesta porque dicho alumnado universitario realice su propio árbol genealógico, a fin de constatar los distintos tipos de unidad familiar existentes en su entorno, o sea que apliquen a su propia experiencia lo que luego van a demandar a sus discentes.

En Educación Primaria las actividades en torno a la familia se han desarrollado atendiendo elementos de la vida cotidiana: ropa, juguetes, elementos del hogar. El alumno percibe los avances tecnológicos en relación a las generaciones que le anteceden (abuelos y padres). Santisteban y Pagès (2011, p. 242) afirman que la historia personal en Primaria sirve para que el alumno construya el tiempo histórico, apoyándose en el manejo de fuentes primarias, el desarrollo de capacidades metacognitivas, las comparaciones cronológicas y simultaneidades históricas. Es decir, que el alumno sea capaz de entender lo que pasaba en el mundo o en su país al mismo tiempo que se producían hechos relevantes de su propia biografía.

Sobre la genealogía y su uso en manuales de Primaria destaca el reciente trabajo de Molina, que llega a conclusiones similares a las ya descritas para Infantil. Es decir una escasa presencia de lo genealógico a la hora de abordar cuestiones familiares, teniendo como primera causa el hecho de que la propia disciplina histórica haya despreciado, hasta finales del siglo XX, la utilidad de las reconstrucciones genealógicas, por considerarlas una 

multicultural y enseñar en valores. El único avance destacable es la desaparición de imágenes sexistas en manuales, que hasta finales del siglo XX perpetuaban la labor de la mujer ligada al hogar. La genealogía apenas se usa en los manuales españoles analizados por Molina, salvo para que los alumnos identifiquen los lazos de parentesco más cercanos (padres, abuelos), lo cual implica el desaprovechamiento de un importante recurso de gran interés a la hora de profundizar en la llamada historia personal (MOLINA, 2011). Quizá la reciente transformación de la sociedad española en multicultural, al pasar de ser un país de emigrantes a un destino de inmigración, explica la diferencia con otras naciones como Reino Unido y Estados Unidos, donde sí abundan estudios sobre el uso didáctico de la familia, por ejemplo los de O'Hara, Cooper, Ferguson, Scabini y Manzi (ORTUÑO; MOLINA; MIRALLES, 2012).

En Secundaria se propugnan ideas similares a las ya comentadas respecto a etapas anteriores, aunque lógicamente dotadas de mayor complejidad, pues las genealogías y recuerdos familiares sirven para relacionar presente personal, pasado familiar, memoria e identidad. Desde la memoria personal a la interpretación histórica de los hechos median varias fases, como la memoria colectiva y, dado que lo que se recuerda no es lo mismo que lo que realmente sucedió, someter esas percepciones subjetivas al método histórico para una correcta interpretación de los hechos. En dicho método hace falta contrastar fuentes primarias orales, escritas y materiales que doten de rigor las conclusiones obtenidas. La diferencia con anteriores etapas educativas radica en que, además de tratar la historia oral, con abuelos o familiares del alumnado que son entrevistados en clase, a esos parientes sería recomendable pedirles documentación que acredite lo que han explicado sobre su infancia y juventud, vida cotidiana, trabajo o postura política: fotografías, cartas, etc. Con eso se elaborará una ficha completa sobre el individuo, que se comparará con la de otros, a fin de detectar semejanzas y diferencias entre personas coetáneas. Dicho trabajo será significativo si se lleva a cabo en pequeños grupos, que con suficiente número de entrevistas (con una serie de preguntas preestablecidas), permitirá 
profesor que queda cada vez más como orientador y planifica actividades que pueden resultar atractivas sobre la vida cotidiana, como por ejemplo las entrevistas a personas mayores.

En resumen, la introducción en distintos niveles educativos de contenidos y actividades que vinculen la historia con cuestiones familiares ha dado resultados positivos, si bien en España no es aún tan frecuente como en el ámbito anglosajón. Las causas de ese relativo éxito residen en el manejo de fuentes primarias y el vínculo entre lo colectivo y lo individual, al hacer ver al alumno que la historia universal y nacional no es algo lejano, sino que influye en la vida de sus parientes y en la suya propia de forma determinante.

\section{Consideraciones finales}

El historiador, salvo contadas excepciones, no consigue sacudir las conciencias de la ciudadanía ya que sus investigaciones, sumamente complejas para el público no especializado, apenas tienen transferencia a la sociedad. Son los docentes de Educación Primaria, Secundaria y Universitaria quienes tienen en su mano sacar a las humanidades incluida la Historia- de ese ostracismo científico al que se les ha empujado. De tal manera que, en primer lugar, hace falta formar a docentes en Historia y otras ciencias sociales. Así podrán salir del currículo y libro de texto que les guía, pero a la vez constriñe, en su quehacer docente. Como siguiente paso, esos maestros mejor formados serán quienes deban transmitir la utilidad e interés práctico de la Historia a sus alumnos, es decir a los futuros ciudadanos. La Historia, y en particular la Historia Social, puede hacer mucho a favor de una ciudadanía crítica y participativa (HEIMBERG, 2005). Este ha de ser el gran reto de la Historia y de la Didáctica de la Historia, es decir, no sólo formar a investigadores o especialistas, que al igual que en otros ámbitos de conocimiento constituyen una minoría ínfima. 
En el caso español esto debería suponer una reaproximación entre historiadores y didactas. Al igual que sucede en el resto de Europa occidental, los historiadores no pueden permitir que su vertiente didáctica quede en manos de profesionales ajenos a ella. Son los historiadores y, por supuesto, aquellos docentes que enseñan Historia en todos los niveles educativos los que deben tomar las riendas de ese proceso, de lo contrario lo disciplinar seguirá siendo irrelevante para la sociedad en general y el ámbito educativo en particular. En esa alianza positiva para investigadores y docentes, lo social y, particularmente, lo familiar tienen mucho que aportar al abrir nuevas vías de estudios interdisciplinares y transversales. Respecto al potencial didáctico de la familia, quizá el gran reto resida en que sirva para una educación no ya multicultural, sino intercultural, al hacer de la diversidad un leit motiv. Los historiadores deben atender otras parcelas, más allá de la investigación erudita y minoritaria, buscando que sus avances tengan significado en la sociedad. Para ello necesitan trabajar de forma conjunta -y habitual- con docentes de ciencias sociales, que deben tratar la Historia no como una mera sucesión de acontecimientos y personajes, sino como la base de una formación en valores cívicos y reflexivos, con el fin de crear un verdadero espíritu ciudadano abierto a visiones críticas. Las experiencias e investigaciones educativas señaladas -muchas de ellas emanadas desde la Universidad de Murcia- han demostrado que es factible y positivo, luego no se trata de simples hipótesis, aunque bien es cierto que no es una práctica frecuente, si bien ensayada en pequeños grupos está dando resultados muy positivos.

\section{Referências}

ALFAGEME, Maria Begoña; MIRALLES, Pedro; MOLINA, Sebastián. Cómo enseñar el concepto de familia en Educación Infantil y Primaria para construir una ciudadanía europea. In: ÁVILA, R. M.; BORGHI, B.; MATOZZI, I. (Eds.). L'educazione alla cittadinanza europea e la formazione degli insegnanti. Bolonia: Pàtron, p. 55-60, 2009.

AMORIN, Maria Norberta. Evolução demográfica de tres paróquias do sul do Pico, 16801980. Braga: Universidade do Minho, 1992.

BARTON, Keith. C. "You'd be wanting to know about the past": social contexts children's historical understanding in Northern Ireland and the United States. Comparative education. New York: Taylor and Francis Group, v. 37, n. 1, p. 89-106, 2001. 
BESTARD CAMPS, Joan. Parentesco y modernidad. Barcelona: Paidós, 1998.

CASANOVA, Julián. La Historia social y los historiadores. Barcelona: Crítica, 1991.

CHACÓN JIMÉNEZ, Francisco. La familia en España, una historia por hacer. In: VILAR, P. (Coord.). La familia en la España Mediterránea (siglos XV-XIX), Barcelona: Crítica,1987, p. 1335 .

CHACÓN JIMÉNEZ, Francisco. Historia social de la familia en España: aproximación a los problemas de familia, tierra y sociedad en Castilla (ss. XV-XIX). Alicante: Instituto Juan Gil Albert, 1990.

CHACÓN JIMÉNEZ, Francisco. Nuevas tendencias de la demografía histórica en España, Boletín de la ADEH. Madrid: ADEH, v. 9, n. 2, p. 79-98, 1991.

CHACÓN JIMÉNEZ, Francisco. Prólogo. In: GARCÍA GONZÁLEZ, F. (Ed.). Historia de la familia en la Península Ibérica (siglos XVI-XIX): balance regional y perspectivas. Homenaje a Peter Laslett. Cuenca: Universidad de Castilla-La Mancha, 2008, p. 8-20.

CHACÓN JIMÉNEZ, Francisco; BESTARD CAMPS, Joan. (Dirs.), Familias:historia de la sociedad española (del final de la Edad Media a nuestros días). Madrid: Cátedra, 2011.

CHACÓN JIMÉNEZ, Francisco; HERNÁNDEZ FRANCO, Juan. (Eds.). Poder, familia y consanguinidad en la España del Antiguo Régimen. Barcelona: Anthropos, 1992.

DOMÍNGUEZ ORTIZ, Antonio. Las clases privilegiadas en el Antiguo Régimen. Madrid: Istmo, 1973.

ESTEPA, Jesús. (Coord.). La educación patrimonial en la escuela y el museo. Investigaciones y experiencias. Huelva: Universidad de Huelva, 2013.

FELIU, M.; HERNÀNDEZ, F. X. Enseñar y aprender historia. Barcelona: Graó, 2011.

FERNÁNDEZ DÍAZ, R. Historia social, historia en construcción. Una década de Historia Social en el modernismo catalán. In: MARTíNEZ SHAW, C. (Ed.). Historia moderna, historia en construcción. Sociedad, política e instituciones. Lérida: Milenio, 1999, p. 7-54.

FERRER I ALÒS, LI. La familia en Cataluña en los siglos XVIII y XIX. Balance y perspectivas. In: GARCÍA GONZÁLEZ, F. (Ed.). Historia de la familia en la Península Ibérica (siglos XVI-XIX). Balance regional y perspectivas. Homenaje a Peter Laslett. Cuenca: Universidad de CastillaLa Mancha, 2008, p. 141-181. 
GARCÍA GONZÁLEZ, F. Presentación. Razones para un balance regional. In: GARCÍA GONZÁLEZ, F. (Ed.). Historia de la familia en la Península Ibérica (siglos XVI-XIX). Balance regional y perspectivas. Homenaje a Peter Laslett. Cuenca: Universidad de Castilla-La Mancha, 2008, p. 23-29.

GÓMEZ, C. J.; MIRALLES, P. La enseñanza de la historia desde un enfoque social. Clío, History and History teaching. Zaragoza: Proyecto Clío, v. 39, 2013. Disponível em: <http://clio.rediris.es>. Acesso em: 20 jan. 2014.

GOZZINI, Giovanni. Génesis y desarrollo de la historia social en Italia. In: CASTILLO, S. (Ed.). La historia social en España: actualidad y perspectivas. Madrid: Siglo XXI, p. 3-25, 1991.

HARAVEN, Tamara. Historia de la familia y la complejidad del cambio social. Boletín de la ADEH. Madrid: ADEH, v. 13, n. 1, p. 99-149, 1995.

HARAVEN, Tamara; PLAKANS, Andrejs. Family history at the crossroads: a journal of family history reader. Princenton: Princeton University Press, 1987.

HEIMBERG, Charles. Vivre la democratie, apprende la democratie. Berne: SER, 2005.

KAYE, Harvey J. Los historiadores marxistas británicos: un análisis introductorio. Zaragoza: Universidad de Zaragoza, 1989.

KERTZER, David; BRETTELL, Caroline. Advances in Italian and Iberian family history. Journal of Family History: studies in family, kinship and demography. Londres: Sage Publications, v. 12, n. 1, p. 87-120, 1987.

LEVI, Giovanni. Prólogo. In: LEVI, G.; RODRÍGUEZ PÉREZ, R. A. (Coords.). Familias, jerarquización y movilidad social. Murcia: UMU, 2010, p. 9-15.

LORENZO PINAR, Francisco Javier. La familia en la historia. Salamanca: Universidad de Salamanca: 2009.

MARAVALL, José Antonio. Poder, honor y élites en el siglo XVII. Madrid: Siglo XXI, 1979.

MILANICH, Nora. Whither Family History? A Road Map from Latin America. American Historical Review. Chicago: Indiana University Press, v. 112, n. 2, p. 439-458, 2007.

MIRALLES, Pedro; DELGADO, Consuelo; CABALLERO, Maria Rosario. Análisis del concepto de familia en las imágenes de los libros de texto de Educación Infantil. Enseñanza de las Ciencias Sociales. Revista de investigación. Barcelona: UB y UAB, v. 7, p. 89-98, 2008. 
MIRALLES, Pedro; MARTÍN, Concepción. Tratamiento didáctico de la familia en los libros de texto y las guías didácticas de educación infantil. Íber. Didáctica de las Ciencias Sociales, Geografía e Historia. Barcelona: Graó, v. 56, p. 111-123, 2008.

MIRALLES, Pedro; MOLINA, Sebastián. Didáctica de las ciencias sociales para el área de Conocimiento del entorno. In: RIVERO GARCÍA, M. P. (Coord.). Didáctica de las ciencias sociales para Educación Infantil. Zaragoza: Mira Editores, 2011, p. 89-110.

MIRALLES, Pedro; MOLINA, Sebastián; ORTUÑO, José. La importancia de la historiografía en la enseñanza de la historia. Granada: Geu, 2011.

MOLINA, Sebastián. "El uso de la genealogía para la enseñanza de la Historia en los niveles educativos iniciales. Clío, History and History teaching. Zaragoza: Proyecto Clío, v. 37, 2011. Disponível em: <http://clio.rediris.es>. Acesso em: 13 jan. 2014.

MOLINA, S.; RODRÍGUEZ, R. A.; SÁNCHEZ, R. Investigar, enseñar y divulgar la historia social: la experiencia del Seminario y grupo de investigación Familia y Élite de Poder de la Universidad de Murcia. Clío, History and History teaching. Zaragoza: Proyecto Clío, v. 39, 2013. Disponível em: <http://clio.rediris.es>. Acesso em: 20 jan. 2014.

MUÑOZ, J. M.Jaume Vicens i Vives una biografia intel·lectual (1910-1960). Barcelona: Edicions 62, 1997.

ORTUÑO, J.; MOLINA, S.; MIRALLES, P. Family Histories and Identites of Integration: The Use of Family Concept in History Classroom in Spanish Kindergarten and Elementary School. The International Journal of Interdisciplinary Social Sciences. Champaign: University of Illinois, v. 6, n. 5, p. 169-184, 2012.

PEIRÓ MARTÍN, I. Historiadores en España. Historia de la historia y memoria de la profesión. Zaragoza: Universidad de Zaragoza, 2013.

PÉREZ GARCÍA, J. M. Familias y hogares en Galicia y en la Cornisa Cantábrica durante el Antiguo Régimen. In: GARCÍA GONZÁLEZ, F. (Ed.). Historia de la Familia en la Península Ibérica (Siglos XVI-XIX). Balance regional y perspectivas. Homenaje a Peter Laslett. Cuenca: Universidad de Castilla-La Mancha,2008,p. 57-84.

PRATS, J.; SANTACANA, J. La historia oral y los documentos fotográficos y audiovisuales. In: PRATS, J. (Coord.). Geografía e Historia. Investigación, innovación y buenas prácticas. Barcelona: Graó, 2011, p. 69-88.

PRO, A.; MIRALLES, P. El currículo de Conocimiento del medio, natural, social y cultural en la educación primaria. Educatio Siglo XXI. Murcia: UMU, v. 27, n. 1, 59-96, 2009. 
REYES, J. L de los. La familia en educación infantil: una propuesta desde las ciencias sociales. In: ÁVILA, R. M.; CRUZ, A.; DÍEZ, C. (Eds.). Didáctica de las ciencias sociales, currículo escolar y formación del profesorado: la didáctica de las ciencias sociales en los nuevos planes de estudio. Jaén: AUPDCS, 2008, p. 357-367.

SANTISTEBAN, A.; PAGÈS, J. Enseñar y aprender el tiempo histórico. In: SANTISTEBAN, A.; PAGÈS, J. (Coords.). Didáctica del conocimiento del medio social y cultural en la educación primaria:ciencias sociales para aprender, pensar y actuar. Madrid: Síntesis: 2011, p. 229-247.

SCULIN, E. El desarrollo de la historia social en la historiografía alemana posterior a 1945. In: CASTILLO, S. (Ed.). La historia social en España: actualidad y perspectivas. Madrid: Siglo XXI, 1991. p. 27-46,

SEIDMAN, M. Social History and Antisocial History. Common Knowledge. Durham: Duke University Press, v. 13, n. 1, 2007, p. 40-49, 2007.

SEIXAS, P.; FROMOWITZ, D.; HILL, P. History, memory and learning to teach. Encounters on Education. Kingston: Queen's University, v. 3, p. 43-59, 2002.

TREPAT, C. A. El aprendizaje del tiempo en educación infantil. In: RIVERO GARCÍA, M. P. (Coord.). Didáctica de las ciencias sociales para Educación Infantil. Zaragoza: Mira Editores, 2011, p. 49-63.

URIA, J. La historia social hoy. Historia Social. Valencia: UNED, v. 60, p. 233-248, 2008.

VAN DER LINDEN, M. Acumulación y fragmentación. Historia Social, Valencia: UNED, v. 60, p. $163-170,2008$. 
Recebido em: 10/01/2014 Aprovado em: 10/03/2014

Universidade do Estado de Santa Catarina - UDESC Programa de Pós-Graduação em História - PPGH

Revista Tempo e Argumento Volume 06 - Número 11 - Ano 2014 tempoeargumento@gmail.com 